\title{
Pluripotent muse cells derived from human adipose tissue: a new perspective on regenerative medicine and cell therapy
}

\author{
Ariel A Simerman, Daniel A Dumesic and Gregorio D Chazenbalk*
}

\begin{abstract}
In 2010, Multilineage Differentiating Stress Enduring (Muse) cells were introduced to the scientific community, offering potential resolution to the issue of teratoma formation that plagues both embryonic stem (ES) and induced pluripotent (iPS) stem cells. Isolated from human bone marrow, dermal fibroblasts, adipose tissue and commercially available adipose stem cells (ASCs) under severe cellular stress conditions, Muse cells self-renew in a controlled manner and do not form teratomas when injected into immune-deficient mice. Furthermore, Muse cells express classic pluripotency markers and differentiate into cells from the three embryonic germ layers both spontaneously and under media-specific induction. When transplanted in vivo, Muse cells contribute to tissue generation and repair. This review delves into the aspects of Muse cells that set them apart from ES, iPS, and various reported adult pluripotent stem cell lines, with specific emphasis on Muse cells derived from adipose tissue (Muse-AT), and their potential to revolutionize the field of regenerative medicine and stem cell therapy.
\end{abstract}

Keywords: Adult pluripotent stem cells; Muse cells; Non-tumorigenic; Quiescence; Regenerative medicine

\section{Review}

Embryonic and induced pluripotent stem cells: the gold standard

ES cells have unequivocally taken center stage in the field of stem cell research. Isolated from human blastocysts in the late 20th century, ES cells exhibited the potential to treat a plethora of previously irreversible disorders through their capacity to generate tissues of the three embryonic germlines, and thus to revolutionize regenerative medicine [1-3]. Their unlimited proliferation as well as their ability to remain in an undifferentiated state for extended periods of time secured their position at the forefront of scientific research for over two decades. However, evidence has since emerged that ES cells exhibit high rates of immunorejection upon transplantation and form teratomas as a result of their unbridled proliferation [4]. In conjunction with debates surrounding the bioethical issues concerning the usage of human embryos, this teratogenic propensity precludes

\footnotetext{
* Correspondence: gchazenbalk@mednet.ucla.edu

Department of Obstetrics and Gynecology, David Geffen School of Medicine
at the University of California, 10833 Le Conte Ave, Box 951740, Los Angeles,

Department of Obstetrics and Gynecology, David Geffen School of Medicine
at the University of California, 10833 Le Conte Ave, Box 951740, Los Angeles, CA 90095-1740, USA
}

the practical application of ES cells in regenerative medicine.

In response, iPS cells quickly assumed their position as the new, fervently pursued subject of interest in the stem cell field $[5,6]$. iPS cells are reprogrammable through the induction of "Yamanaka factors," including Nanog, Oct3/4, Sox2, c-Myc and Klf4, and can be utilized autologously, resolving issues of immunorejection at the time of transplantation [6-9]. While iPS cells resolve the bioethical concerns surrounding the use of stem cells extracted from human embryos, the production of teratomas as a consequence of uncontrolled cell proliferation impede the translational application of these cells for stem cell therapy [10,11]. Furthermore, mature iPS cells possess an epigenetic memory, wherein the remnants of posttranslational histone and DNA modifications prevent complete reprogramming as well as their physiological function beyond the range of their cell type of origin [7,12-14]. Investigators have made attempts to address these issues, but to little avail $[15,16]$. Despite excessive monetary and temporal efforts devoted to the study of both ES cells and iPS cells, there has 
been little progress made in overcoming the hurdles facing these stem cells and their use towards cell therapy.

\section{Adult pluripotent stem cells at a glance}

Other, non-reprogrammed pluripotent stem cell populations have caught the attention of the scientific community as an alternative to ethically contentious ES cells and genetically modified iPS cells. However, though several populations of adult stem cells that possess pluripotency have been put forth, many have faced a great deal of suspicion due to irreproducibility and pluripotency marker identification. Isolated from bone marrow, multipotent adult progenitor cells (MAPCs), both pluripotent and non-tumorigenic, were reported to contribute to chimeric offspring when injected into a mouse model and to regenerate damaged tissue in vivo $[17,18]$. Human marrow-isolated adult multilineage inducible (MIAMI) cells and very small embryonic-like stem cells (VSELs), isolated from umbilical cord blood in addition to bone marrow, were soon to follow, exhibiting similar pluripotent and non-tumorigenic properties [17-19]. Like VSELs, unrestricted somatic stem cells (USSCs), isolated from umbilical cord blood, are reportedly pluripotent but lack the classic pluripotent stem cell marker expression [20]. These adult pluripotent stem cell lines have all been publically flagged for further investigation and reproduction, or in the case of VSELs, negated entirely [21,22].

Stimulus-triggered acquisition of pluripotency (STAP), characterized by exposing splenic CD45+ lymphocytes to acidic conditions followed by incubation with leukaemia inhibitory factor (LIF), has recently been described as a method of bestowing pluripotency upon somatic cells [23]. However, STAP cells form teratomas, hindering their clinical application. STAP cells are currently under investigation to determine the overall validity of the published results as well as the mechanism behind their reprogramming.

\section{The advent of muse cells}

In 2010, a research team at the Tohoku University in Sendai, Japan, identified a population of pluripotent mesenchymal stem cells (MSCs), named Multilineage Differentiating Stress Enduring (Muse) cells, through the induction of severe cellular stress. Initially isolated from bone marrow aspirates and human skin fibroblasts, this cell population expresses the pluripotency marker stage-specific embryonic antigen-3 (SSEA-3) as well as the mesenchymal cell marker CD105 [24,25]. Our research team at the University of California, Los Angeles, discovered that Muse cells exist in human adipose tissue as well [26]. Imposing alternate, yet comparably high stress conditions, we isolated Muse cells, derived from adipose tissue harvested by lipoaspiration (Muse-AT cells) [26]. More recently, investigators have shown that Muse cells can be isolated from commercially available human adipose stem cells (ASCs) through SSEA-3 cell sorting as well [27]. Much like their relatives derived from bone marrow aspirates and skin fibroblasts [24], Muse-AT cells form cell clusters similar to ES cells when grown in suspension. Muse-AT cells also express the classic pluripotency markers SSEA3, Sox2, Oct3/4, Nanog and TRA1-81 [24,26].

\section{Pluripotency of muse cells in vitro and in vivo}

Muse cells grow in suspension as cell clusters reminiscent of embryonic stem cells. Muse cells intrinsically express classic pluripotency markers including SSEA3, Nanog, Oct3/4, Sox2, TRA1-60 and TRA1-81 [24,26]. Furthermore, Muse cells, both spontaneously and under specific culture conditions, express mesodermal ( $\alpha$-smooth muscle actin, desmin, DLK, Bodipy and myosin D), endodermal ( $\alpha$-fetoprotein, cytokeratin 7, GATA6 and pan keratin), and ectodermal (neurofilament-M, MAP2, Glut-R, and NeuroD) markers [24,26]. Intravenously administered GFP-labeled human Muse cells injected into damaged skin, muscle, and liver tissue of immunodeficient mice were able to integrate and differentiate accordingly in vivo and contribute vastly to tissue regeneration within 2-4. weeks [24]. Human Muse cells were successfully applied in models of fulminant hepatitis, muscle degeneration and skin injury in different mouse-disease models [21].

Muse cells, induced to grow into 3D cultured skin in vitro, have the capacity to give rise to mature melanocytes, contributing to tissue regeneration after engraftment into damaged skin [28]. The authenticity of Muse-derived melanocytes is supported both molecularly and morphologically. Muse-derived melanocytes were pigmented, as compared to the negative control. Furthermore, they differentially expressed human melanocyte markers. This evidence suggests that various skin diseases due to melanocyte dysfunction, including the prevalent vitiligo, could be treated using Muse-derived melanocyte transplantations.

\section{Muse cells and non-tumorigenicity: a scientific anomaly}

The definition of pluripotency relies upon a cell's ability to differentiate into the three embryonic germ layers, and in the case of stem cells, to self-renew [29]. Tumor formation coincides with both pluripotency and self-renewal and has emerged as a critical factor in determining the pluripotent capacities of both ES and iPS cells [30-33]. However, as seen in ES and iPS cells, the capacity for tripoblastic differentiation and self-renewal is frequently uncontrolled, and often materializes in teratoma formation, hindering the exploitation of their pluripotency for regenerative purposes. However, innate pluripotent stem cells, including epiblast stem cells and neoblasts present in planarians, do not form teratomas in the way that ES and iPS cells do [34]. Planarians and newts, which have the ability to regenerate amputated 
body parts, have also been shown to possess pluripotent cells [35].

Despite their characterization as pluripotent stem cells, Muse cells exhibit both low proliferative and telomerase activities, a normal karyotype as well as asymmetric division, and thus do not undergo tumorigenesis or teratoma formation when transplanted into a host organism $[24,26,27]$ (Figure 1). Low telomerase activity is partially responsible for this peculiar balance [27]. Muse cells also exhibit much lower expression of the so-called "Yamanaka factors" in comparison with iPS cells $\left(>10^{5}\right.$ fold decrease) [25]. Furthermore, Muse cells exhibit a slight increase in expression of Sox2, Nanog, Oct3/4 as compared to nonmuse cells $(2-4$ fold $)[24,26]$. Intermediate expression of the genes that have been shown to confer pluripotency and teratogenesis may explain how Muse cells retain their lineage plasticity while simultaneously negating teratoma formation.

Lin28, a RNA-binding protein gene, maintains both pluripotency and tumorigenesis in ES and iPS cells [36,37]. Let-7, a microRNA that regulates embryonic development, cell differentiation and tumor suppression, has the opposite effect [37]. While over-expression of Let-7 blocks Lin28 gene expression, Lin28 expression degrades Let-7, maintaining a balance in their expression, controlling development and disease [37]. Levels of Lin28 expression decline over the course of embryonic development while let-7 miRNA's simultaneously increase, suppressing selfrenewal of undifferentiated cells and stimulating cell differentiation. ES and iPS cells have a very high Lin28/Let7 ratio, which has been thought to play a major role in their tumorigenic propensities [37]. In the absence of a strong Lin28 influence, Muse cells retain their pluripotent capacity [25]. Over-expression of Let-7 in Muse cells would potentially play a critical role in inhibiting Lin 28 expression, and therefore would protect these cells from tumorigenic proliferation and teratoma formation after in vivo transplantation.

Retaining their self-renewing ability, Muse cells do not undergo unbridled proliferation or tumor formation in vivo, setting them apart from ES cells. When transplanted into the testes of immune-deficient mice, Muse cells did not form teratomas while ES cells formed large teratomas within 8-10 weeks [27]. As pluripotency and tumorigenesis have commonly been considered a packaged deal, it is imperative to consider what factors allow Muse cells to avoid tumor formation while retaining their capacity for differentiation into all three germ lineages.

It has been postulated that iPS cells are generated exclusively from Muse cells [25]. When fibroblasts were subjected to the Yamanaka factors, only Muse cells
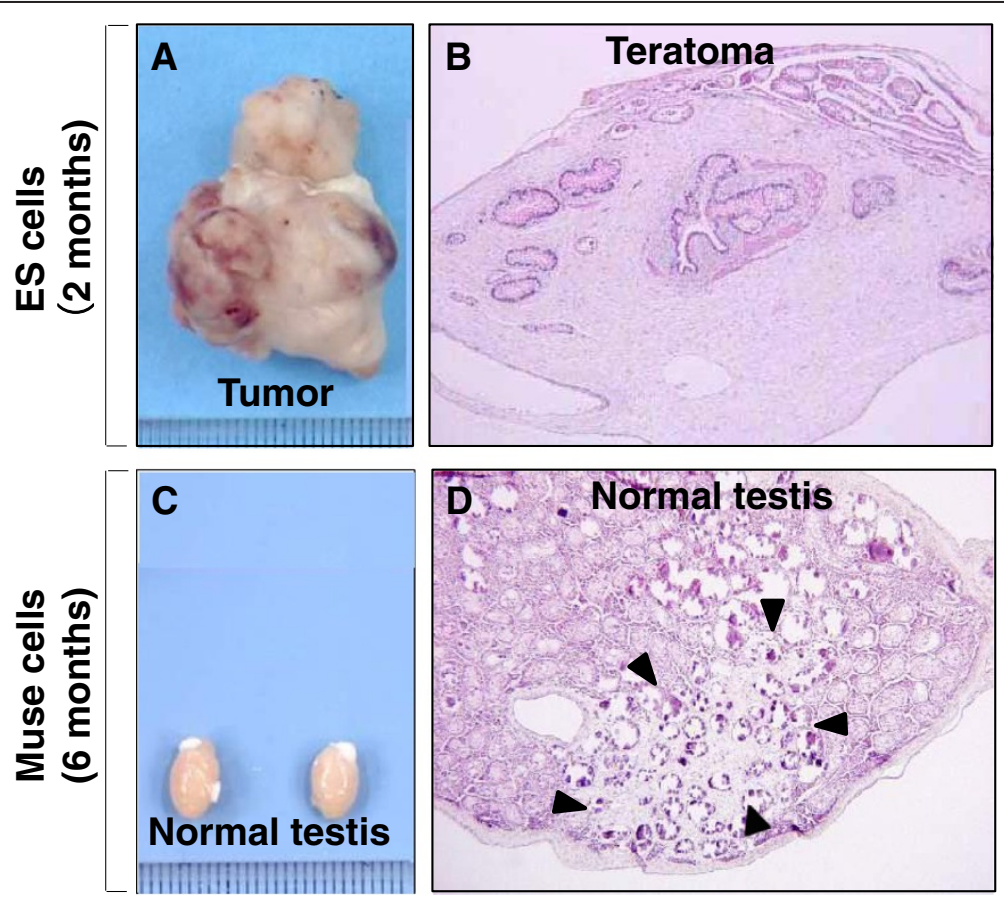

Figure 1 Non-tumorigenicity of Muse cells. (A) Embryonic stem (ES) cells infused into immunodeficient mice (SCID mice) testes, formed teratomas within 8 to 12 weeks, (B) Histological analysis showed that the teratoma contained muscle tissue, intestine-like structures and keratinized skin, (C) Muse cell-transplanted testes did not generate teratomas similar to untreated testes, and (D) Testes injected with Muse cells maintained normal structure even 6 months post-injection (Pictures reproduced from Proc Natl Acad Sci USA 2010, 107: 8639-43, and Stem Cells Dev 2014 DOI: $10.1089 / \mathrm{scd} .2013 .0473)$. 
underwent successful iPS cell generation [25]. Gene analysis shows that classical markers of tumorigenesis, including BCR1, CCMB1 and CCMB2, are highly expressed in iPS cells derived from Muse cells as compared to naïve Muse cells [25]. In contrast, CDKN1A and CDKN2A, involved in tumor suppression, are highly expressed in Muse cells versus iPS cells derived from Muse cells [25]. This may shed light on the effects of the induction of the Yamanaka factors and their contribution to tumorigenesis, as well as the inherent propensity for teratoma formation in iPS cells but not Muse cells, however further studies are required to elucidate this distinction.

Muse cells derived from adipose tissue (Muse-AT)

We isolated Muse cells derived from adipose tissue harvested by lipoaspiration (Muse-AT cells) under severe cellular stress conditions [26]. Furthermore, Muse cells isolated from adipose tissue can be also obtained from commercially available human adipose stem cells (ASCs) through SSEA-3 cell sorting [27]. Much like their relatives derived from bone marrow aspirates and skin fibroblasts [24], Muse-AT cells grow in suspension as cell clusters, similar to embryoid bodies, which express the classic pluripotency markers SSEA3, Sox2, Oct3/4, Nanog, and TRA1-60 [24,26] (Figure 2).

Under unperturbed physiological circumstances, MuseAT cells reside within the adipocyte and stromal vascular fractions [26]. Within both fractions, cross-talk between ASCs and adipose tissue-residing macrophages (ATMs) contributes to cell plasticity, adipogenesis and ASC formation [39] (Figure 3). ASCs, ATMs and adipose immune infiltrating cells may interact with neighboring Muse-AT cells, affecting their lineage plasticity, adipose tissue

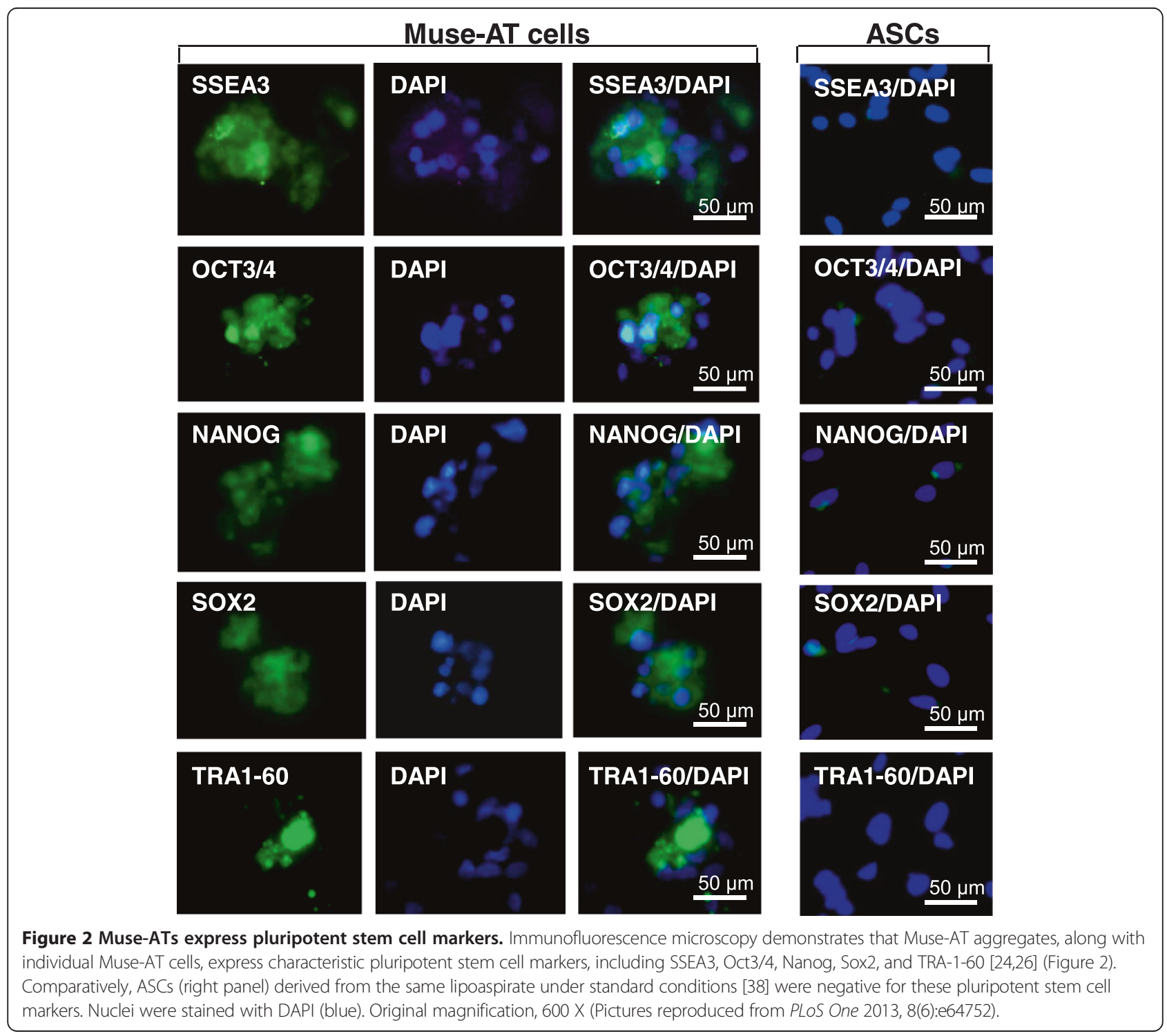




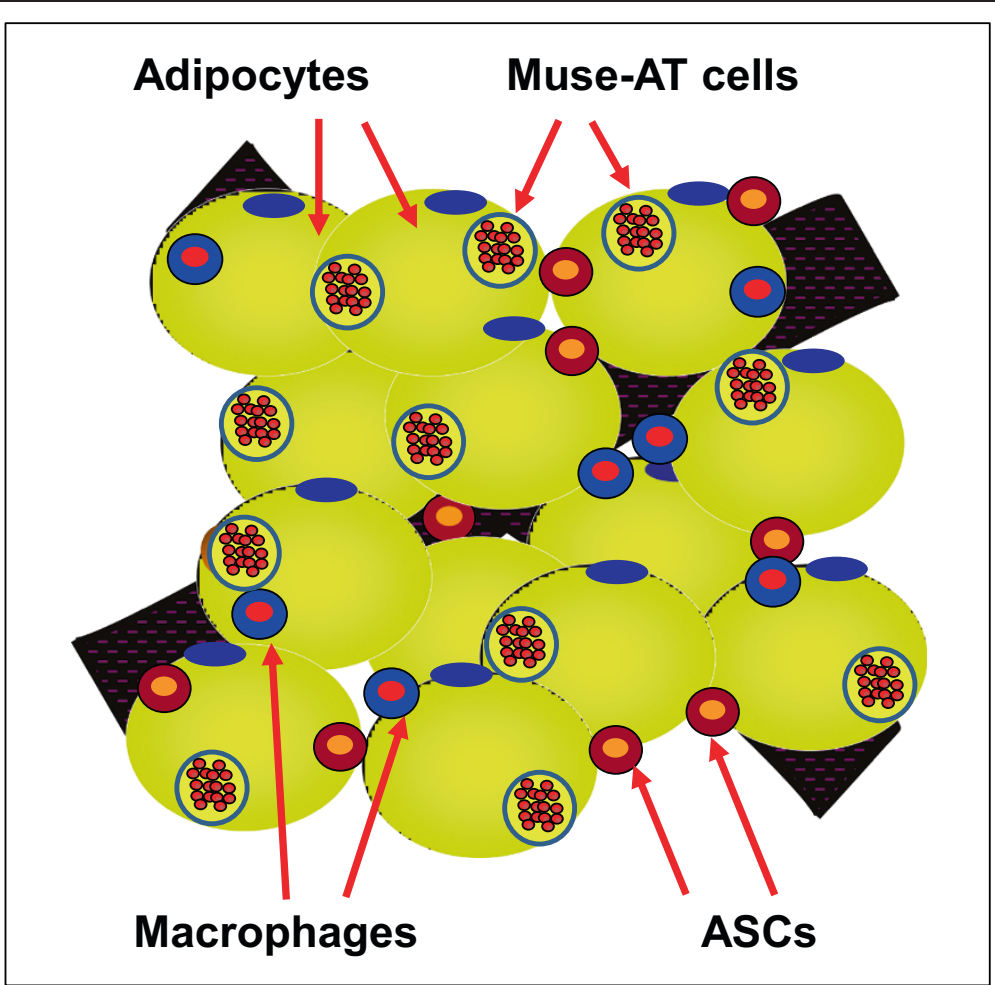

Figure 3 Graphical depiction of different cell components present in adipose tissue. Adipose tissue is composed of adipocytes and the stromal vascular fraction containing adipose tissue macrophages (ATMs), adipose stem cells (ASCs) and Muse-AT cells, among other cell components.

differentiation and repair, and the production and recruitment of signaling molecules in times of cellular stress [26].

Muse-AT cells differentiate into mesodermal, endodermal and ectodermal embryonic germ lineages spontaneously, with $23 \%, 20 \%$ and $22 \%$ respective efficiencies [26]. Incubated in the presence of lineage-specific media, Muse-AT cells differentiate with $82 \%, 75 \%$ and $78 \%$ respective efficiencies. Furthermore, Muse-AT cells exhibit lineage-specific morphological characteristics after only 3 days in culture [26]. Immunocytochemistry studies showed expression of markers for adipocytes, myocytes, hepatocytes and neural cells in both naïve Muse cells and Muse cells that had been induced to differentiation in tissue-specific culture media [26]. For example, Muse-AT cells demonstrated formation of lipid droplets when induced to differentiate into adipocytes (Figure 4A), as well as characteristic smooth muscle striations when induced to differentiate into myocytes (Figure 4B) [26]. Employing identical culture conditions used to induce ES and iPS differentiation into hepatocytes, Muse-AT cells were also driven to differentiate into hepatocyte-like cells (Figure 4C) [26]. Furthermore, Muse-AT cells differentiate into neurallike cells, forming long, finger-like projections, typical of neurons, similar to ES and iPS cells (Figure 4D) [26]. Muse-AT cells could therefore be applied to treat muscle, liver and brain disorders without the teratogenic risk associated with ES and iPS cells.

Genes associated with cell death and survival, embryonic development, organismal development, tissue development, cellular assembly and organization, and cellular function and maintenance are highly conserved, with homologues present in numerous primordial organisms including yeast (S. Cerevisiae), C. elegans, chlamydomonas, T. californica, and fruit fly (Drosophila). Muse-AT cells differentially express genes from all of the aforementioned categories, suggesting that Muse cells may function according to a highly conserved cellular mechanism related to cell survival in response to severe cellular stress $[40,41]$.

For medical and cosmetic reasons, lipoaspirate material is routinely extracted from the human body due to its availability, accessibility and abundance. Because adipose tissue is present in such a high abundance within the human body, the number of extractable Muse-AT cells is abundant compared to that which can be extracted from bone marrow or dermis. Muse-AT cell isolation from lipoaspirate material is both temporally and monetarily efficient.

\section{Muse-AT cells and quiescence}

Muse cells exist in a quiescent state under normal physiological circumstances within the cellular niche 

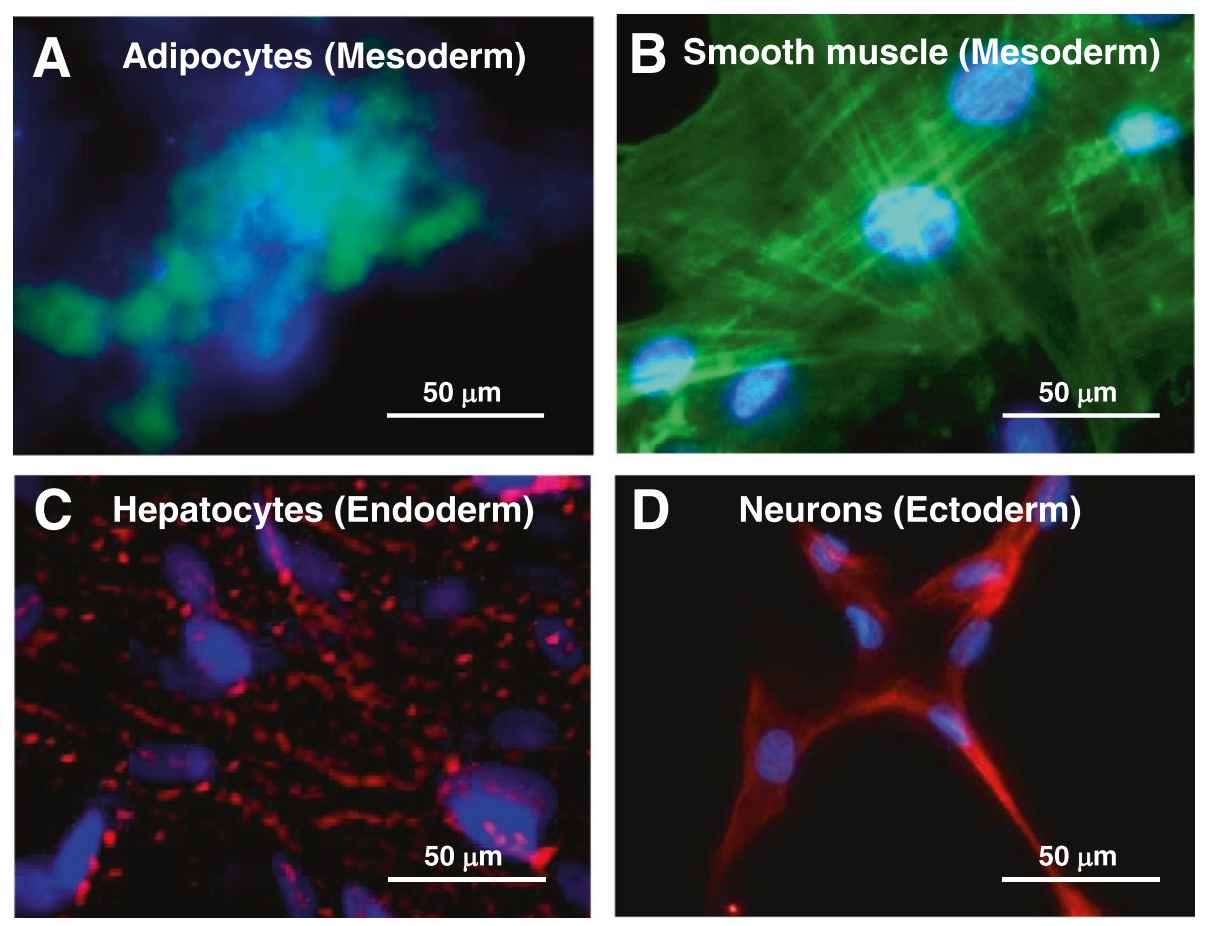

Figure 4 Tripoblastic characteristics of Muse-AT cells. Muse-AT cells were grown as adherent cells in the presence of (A) adipogenic medium; the formation of adipocytes was detected using BODYI-PI-C16 which identify lipid drops present in adipocytes; (B) myogenic differentiation medium; the formation of myocytes was detected using an anti-human MSA antibody; (C) hepatogenic differentiation medium; formation of hepatocytes was detected using an anti-cytokeratin 7 antibody; (D) Muse-AT cells were grown for 7 days as non-adherent cells and then cultured for an additional 7 days as adherent cells; neural-like cells were detected by immunofluorescence using an anti-human MAP2 antibody. Nuclei were stained with DAPI (blue). Original magnification was 600X. (Pictures reproduced from PLoS One 2013, 8(6):e64752).

prior to cellular stress disruption [24,26]. Contributing to their capacity for self-renewal, multiple adult stem cell lineages have been shown to exist in a quiescent state, including hematopoietic stem cells and epithelial stem cells $[42,43]$. The mobilization of quiescent stem cells is attributed to CXCL2, a chemokine, which functions in stem cell homing [43]. Exposing MSCs to CXCL2 prior to transplantation increases post-transplant stem cell survival rates in cases of myocardial infarction [44]. In the case of Muse-AT cells, CXCL2 is expressed 770 folds higher than in neighboring ASCs, which could therefore explain their genetic predisposition to cellular stress resistance [22]. CXCL2, overexpressed in cancer cells, contributes both to cancer cell survival and malignancy. Quiescence is the "natural" state in which Muse cells exist. On the other hand, quiescence contributes to the maintenance of malignancy in cancer stem cells in a dormant stage, susceptible to relapse in the wake of cancer treatment [36]. The internal/external stimuli that activate Muse cells (prolonged treatment with proteolytic enzymes, lack of nutrients, low temperatures, hypoxia) are entirely different than those that activate cancer stem cells (ionizing radiation, ultraviolet radiation, chemical compounds, reactive oxygen species, error prone DNA repair, among others).
Nevertheless, Muse cells (non-tumorigenic cells) can be converted into iPS cells (tumorigenic cells) when exposed to the four "Yamanaka factors" [25].

Microarray analysis showed differential expression of 144 critical genes involved in cell death and survival (e.g. SGK1, MDH1, ATF2, HSPA8, PDIA3, BRD1, CALM1, NR4A2, GATA2, CDK6, NUF2, CDK6, BRC1, BUB1B and CXCL2), suggesting that expression of these genes could contribute to Muse-AT cell activation from quiescence [26]. Furthermore, Muse-AT cells over-express ALDH1A2 (47 fold change versus ASCs) and SOD2 (41 fold change versus ASCs) which boast anti-oxidative stress and anti-apoptotic functions [44,45]. Interestingly, DNA repair genes are generally up-regulated in MuseAT cells, indicating a high capacity to resist DNA damage due to cellular stress [26].

The application of stem cells in regenerative medicine has often been impeded by a low survival rate $(<3 \%)$, when exposed to the high stress environment of the engraftment site, especially in cases of myocardial infarction, ischemic injury and stroke [40,46-50]. Investigators have utilized hypoxia preconditioning (HPC), a process in which stem cells are introduced to hypoxic conditions for 24-48 hours prior to transplantation, to acclimatize 
stem cells to pro-apoptotic factors including hypoxia, malnutrition, pro-inflammatory cytokines and reactive oxygen and nitrogen species, in order to enhance post-transplantation stem cell survival [51-53]. Muse cells, however, do not require HPC or any other pre-transplantation conditioning, as they are intrinsically resilient to cellular stress $[24,26]$. A long-term trypsin (LTT) incubation, or proteolytic digestion, was employed to isolate Muse cells from bone marrow aspirates and skin fibroblasts [24]. Human adipose tissue lipoaspirate material was subjected to even more severe cellular stress conditions including long-term exposure to the proteolytic enzyme collagenase (LTC), serum deprivation, low temperatures and hypoxia. This, in turn, produced a highly purified population of Muse (Muse-AT) cells [26]. As cellular stress induction is imperative to Muse cell isolation, and thus intrinsic to their activation, their capacity for survival and the ultimate translational objective of tissue regeneration in vivo is greater as compared to alternative stem cell populations.

\section{Conclusions}

The potential application of Muse cells in regenerative stem cell therapies is both innovative and promising. Muse cells are inherently resistant to cellular stress, and genetically resilient to DNA damage, supporting their application for the investigation of age-related and degenerative diseases. Moreover, because Muse cells possess a pre-perturbation and an intrinsic propensity for quiescence, they may have the potential to elucidate new avenues of cancer research, specifically with regards to the mechanism behind quiescence, and malignancy $[26,43]$. Finally, and perhaps most thrillingly, Muse cells could be harvested for the purposes of creating autologous stem cell banks. Because of their differentiation capacity, Muse cells could be utilized to regenerate any type of tissue and thus treat neurological and immune disorders, and injuries to critical organs such as the heart and brain.

Furthermore, Muse-AT cells are isolated from lipoaspirate material which is easily accessible, abundant, and non-invasively extracted from the human body for both medical and cosmetic purposes. Hundreds of millions of adipose cells can be extracted from a mere 1-2 liters of tissue, enhancing the number of extractable Muse-AT cells. Muse-AT cells are a promising candidate for translational application in stem cell therapy and regenerative medicine, thus it is imperative to further investigate and exploit their unique qualities and vast potential.

\section{Competing interests}

The authors declare that they have no competing interests.

\section{Authors' contribution}

$A A S, D A D$, and GDC contributed to the writing of this review. All authors read and approved the final manuscript.

\section{Grant support}

Supported in part by the Eunice Kennedy Shriver National Institute of Child Health \& Human Development, the National Institutes of Health through the cooperative agreement U54 HD071836 and by the UCLA Department of

Obstetrics and Gynecology.

Received: 8 April 2014 Accepted: 14 May 2014

Published: 22 May 2014

\section{References}

1. Evans MJ, Kaufman MH: Establishment in culture of pluripotential cells from mouse embryos. Nature 1981, 292(5819):154-156.

2. Martin GR: Isolation of a pluripotent cell line from early mouse embryos cultured in medium conditioned by teratocarcinoma stem cells. Proc Natl Acad Sci U S A 1981, 78(12):7634-7638.

3. Thomson JA, Itskovitz-Eldor J, Shapiro SS, Waknitz MA, Swiergiel JJ, Marshall VS, Jones JM: Embryonic stem cell lines derived from human blastocysts. Science 1998, 282(5391):1145-1147.

4. Przyborski SA: Differentiation of human embryonic stem cells after transplantation in immune-deficient mice. Stem Cells 2005, 23(9):1242-1250

5. Maherali N, Sridharan R, Xie W, Utikal J, Eminli S, Arnold K, Stadtfeld M, Yachechko R, Tchieu J, Jaenisch R, Plath K, Hochedlinger K: Directly reprogrammed fibroblasts show global epigenetic remodeling and widespread tissue contribution. Cell Stem Cell 2007, 1(1):55-70.

6. Takahashi K, Yamanaka S: Induction of pluripotent stem cells from mouse embryonic and adult fibroblast cultures by defined factors. Cell 2006, 126(4):663-676.

7. Plath K, Lowry WE: Progress in understanding reprogramming to the induced pluripotent state. Nat Rev Genet 2011, 12(4):253-265.

8. Power C, Rasko JE: Promises and challenges of stem cell research for regenerative medicine. Ann Intern Med 2011, 155(10):706-713. W217.

9. Stadtfeld M, Hochedlinger K: Induced pluripotency: history, mechanisms, and applications. Genes Dev 2010, 24(20):2239-2263.

10. Fong CY, Gauthaman K, Bongso A: Teratomas from pluripotent stem cells: A clinical hurdle. J Cell Biochem 2010, 111(4):769-781.

11. Geng YJ: Molecular mechanisms for cardiovascular stem cell apoptosis and growth in the hearts with atherosclerotic coronary disease and ischemic heart failure. Ann N Y Acad Sci 2003, 1010:687-697.

12. Hanna J, Saha K, Pando B, van Zon J, Lengner CJ, Creyghton MP, van Oudenaarden $A$, Jaenisch $R$ : Direct cell reprogramming is a stochastic process amenable to acceleration. Nature 2009, 462(7273):595-601.

13. Kim J, Woo AJ, Chu J, Snow JW, Fujiwara Y, Kim CG, Cantor AB, Orkin SH: A Myc network accounts for similarities between embryonic stem and cancer cell transcription programs. Cell 2010, 143(2):313-324.

14. Smith ZD, Nachman I, Regev A, Meissner A: Dynamic single-cell imaging of direct reprogramming reveals an early specifying event. Nat Biotechnol 2010, 28(5):521-526

15. Kim D, Kim CH, Moon Jl, Chung YG, Chang MY, Han BS, Ko S, Yang E, Cha KY, Lanza R, Kim KS: Generation of human induced pluripotent stem cells by direct delivery of reprogramming proteins. Cell Stem Cell 2009, 4(6):472-476.

16. Yu J, Hu K, Smuga-Otto K, Tian S, Stewart R, Slukvin II, Thomson JA: Human induced pluripotent stem cells free of vector and transgene sequences. Science 2009, 324(5928):797-801.

17. Jiang Y, Jahagirdar BN, Reinhardt RL, Schwartz RE, Keene CD, Ortiz-Gonzalez XR, Reyes M, Lenvik T, Lund T, Blackstad M, Du J, Aldrich S, Lisberg A, Low WC, Largaespada DA, Verfaillie CM: Pluripotency of mesenchymal stem cells derived from adult marrow. Nature 2002, 418(6893):41-49.

18. Dimomeletis I, Deindl E, Zaruba M, Groebner M, Zahler S, Laslo SM, David R, Kostin S, Deutsch MA, Assmann G, Mueller-Hoecker J, Feuring-Buske M, Franz WM: Assessment of human MAPCs for stem cell transplantation and cardiac regeneration after myocardial infarction in SCID mice. Exp Hematol 2010, 38(11):1105-1114.

19. Kucia M, Zuba-Surma EK, Wysoczynski M, Wu W, Ratajczak J, Machalinski B, Ratajczak MZ: Adult marrow-derived very small embryonic-like stem cells and tissue engineering. Expert Opin Biol Ther 2007, 7(10):1499-1514.

20. Santourlidis S, Wernet P, Ghanjati F, Graffmann N, Springer J, Kriegs C, Zhao X, Brands J, Arauzo-Bravo MJ, Neves R, Koegler G, Uhrberg M: Unrestricted somatic stem cells (USSC) from human umbilical cord blood display 
uncommitted epigenetic signatures of the major stem cell pluripotency genes. Stem Cell Res 2011, 6(1):60-69.

21. Miyanishi M, Mori Y, Seita J, Chen JY, Karten S, Chan CK, Nakauchi H, Weissman IL: Do pluripotent stem cells exist in adult mice as very small embryonic stem cells? Stem Cell Reports 2013, 1(2):198-208.

22. Prockop DJ: Repair of tissues by adult stem/progenitor cells (MSCs): controversies, myths, and changing paradigms. Mol Ther 2009, 17(6):939-946

23. Obokata H, Wakayama T, Sasai Y, Kojima K, Vacanti MP, Niwa H, Yamato M, Vacanti CA: Stimulus-triggered fate conversion of somatic cells into pluripotency. Nature 2014, 505(7485):641-647.

24. Kuroda Y, Kitada M, Wakao S, Nishikawa K, Tanimura Y, Makinoshima H, Goda M, Akashi H, Inutsuka A, Niwa A, Shigemoto T, Nabeshima Y, Nakahata T, Nabeshima Y, Fujiyoshi Y, Dezawa M: Unique multipotent cells in adult human mesenchymal cell populations. Proc Natl Acad Sci U S A 2010, 107(19):8639-8643.

25. Wakao S, Kitada M, Kuroda Y, Shigemoto T, Matsuse D, Akashi H, Tanimura Y, Tsuchiyama K, Kikuchi T, Goda M, Nakahata T, Fujiyoshi Y, Dezawa M: Multilineage-differentiating stress-enduring (Muse) cells are a primary source of induced pluripotent stem cells in human fibroblasts. Proc Nat Acad Sci U S A 2011, 108(24):9875-9880

26. Heneidi S, Simerman AA, Keller E, Singh P, Li X, Dumesic DA, Chazenbalk G Awakened by cellular stress: isolation and characterization of a novel population of pluripotent stem cells derived from human adipose tissue. PLoS One 2013, 8(6):e64752.

27. Ogura F, Wakao S, Kuroda Y, Tsuchiyama K, Bagheri M, Heneidi S, Chazenbalk G, Aiba S, Dezawa M: Human adipose tissue possesses a unique population of pluripotent stem cells with non-tumorigenic and low telomerase activities: potential implications in regenerative medicine. Stem Cells Dev 2013, 23(7):717.

28. Tsuchiyama K, Wakao S, Kuroda Y, Ogura F, Nojima M, Sawaya N, Yamasaki K, Aiba S, Dezawa M: Functional melanocytes are readily reprogrammable from multilineage-differentiating stress-enduring (muse) cells, distinct stem cells in human fibroblasts. J Invest Dermatol 2013, 133(10):2425-2435.

29. Wesselschmidt RL: The teratoma assay: an in vivo assessment of pluripotency. Methods Mol Biol 2011, 767:231-241.

30. Ben-David U, Benvenisty N: The tumorigenicity of human embryonic and induced pluripotent stem cells. Nat Rev Cancer 2011, 11(4):268-277.

31. Gutierrez-Aranda I, Ramos-Mejia V, Bueno C, Munoz-Lopez M, Real PJ, Macia A, Sanchez L, Ligero G, Garcia-Parez JL, Menendez P: Human induced pluripotent stem cells develop teratoma more efficiently and faster than human embryonic stem cells regardless the site of injection. Stem Cells 2010, 28(9):1568-1570.

32. Lee AS, Tang C, Rao MS, Weissman IL, Wu JC: Tumorigenicity as a clinical hurdle for pluripotent stem cell therapies. Nat Med 2013, 19(8):998-1004

33. Ohm JE, Mali P, Van Neste L, Berman DM, Liang L, Pandiyan K, Briggs KJ, Zhang W, Argani P, Simons B, Yu W, Matsui W, Van Criekinge W, Rassool FV, Zambidis E, Schuebel KE, Cope L, Yen J, Mohammad HP, Cheng L, Baylin SB: Cancer-related epigenome changes associated with reprogramming to induced pluripotent stem cells. Cancer Res 2010, 70(19):7662-7673.

34. Gentile L, Cebria F, Bartscherer K: The planarian flatworm: an in vivo model for stem cell biology and nervous system regeneration. Dis Model Mech 2011, 4(1):12-19.

35. Tanaka EM, Reddien PW: The cellular basis for animal regeneration. Dev Cell 2011, 21(1):172-185.

36. Marson A, Levine SS, Cole MF, Frampton GM, Brambrink T, Johnstone S, Guenther MG, Johnston WK, Wernig M, Newman J, Calabrese JM, Dennis LM, Volkert TL, Gupta S, Love J, Hannett N, Sharp PA, Bartel DP, Jaenisch R, Young RA: Connecting microRNA genes to the core transcriptional regulatory circuitry of embryonic stem cells. Cell 2008, 134(3):521-533.

37. Thornton JE, Gregory RI: How does Lin28 let-7 control development and disease? Trends Cell Biol 2012, 22(9):474-482.

38. Zuk PA, Zhu M, Mizuno H, Huang J, Futrell JW, Katz AJ, Benhaim P, Lorenz $H P$, Hedrick MH: Multilineage cells from human adipose tissue: implications for cell-based therapies. Tissue Eng 2001, 7(2):211-228.

39. Chazenbalk G, Bertolotto C, Heneidi S, Jumabay M, Trivax B, Aronowitz J, Yoshimura K, Simmons CF, Dumesic DA, Azziz R: Novel pathway of adipogenesis through cross-talk between adipose tissue macrophages, adipose stem cells and adipocytes: evidence of cell plasticity. PLoS One 2011, 6(3):e17834.
40. Kultz D: Molecular and evolutionary basis of the cellular stress response. Annu Rev Physiol 2005, 67:225-257.

41. Meier P, Finch A, Evan G: Apoptosis in development. Nature 2000, 407(6805):796-801.

42. Blanpain C, Lowry WE, Geoghegan A, Polak L, Fuchs E: Self-renewal, multipotency, and the existence of two cell populations within an epithelial stem cell niche. Cell 2004, 118(5):635-648.

43. Li L, Bhatia R: Stem cell quiescence. Clin Cancer Res 2011, 17(15):4936-4941.

44. Huang J, Zhang Z, Guo J, Ni A, Deb A, Zhang L, Mirotsou M, Pratt RE, Dzau VJ: Genetic modification of mesenchymal stem cells overexpressing CCR1 increases cell viability, migration, engraftment, and capillary density in the injured myocardium. Circ Res 2010, 106(11):1753-1762

45. Vasiliou V, Nebert DW: Analysis and update of the human aldehyde dehydrogenase (ALDH) gene family. Hum Genomics 2005, 2(2):138-143.

46. Dayem AA, Choi HY, Kim JH, Cho SG: Role of oxidative stress in stem cancer, and cancer stem cells. Cancers (Basel) 2010, 2(2):859-884.

47. Hodgetts SI, Beilharz MW, Scalzo AA, Grounds MD: Why do cultured transplanted myoblasts die in vivo? DNA quantification shows enhanced survival of donor male myoblasts in host mice depleted of CD4+ and CD8+ cells or Nk1.1+ cells. Cell Transplant 2000, 9(4):489-502.

48. Hofmann M, Wollert KC, Meyer GP, Menke A, Arseniev L, Hertenstein B, Ganser A, Knapp WH, Drexler H: Monitoring of bone marrow cell homing into the infarcted human myocardium. Circulation 2005, 111(17):2198-2202

49. Mingliang R, Bo Z, Zhengguo W: Stem cells for cardiac repair: status, mechanisms, and new strategies. Stem Cells Int 2011, 2011:310928.

50. Oh JS, Kim KN, An SS, Pennant WA, Kim HJ, Gwak SJ, Yoon Do H, Lim MH, Choi BH, Ha Y: Cotransplantation of mouse neural stem cells (mNSCs) with adipose tissue-derived mesenchymal stem cells improves mNSC survival in a rat spinal cord injury model. Cell Transplant 2010, 20(6):837-849

51. Abdollahi $H$, Harris $\sqcup$, Zhang $P$, Mcllhenny $S$, Srinivas $V$, Tulenko T, DiMuzio PJ: The role of hypoxia in stem cell differentiation and therapeutics. J Surg Res 2009, 165(1):112-117.

52. Chacko SM, Ahmed S, Selvendiran K, Kuppusamy ML, Khan M, Kuppusamy P: Hypoxic preconditioning induces the expression of prosurvival and proangiogenic markers in mesenchymal stem cells. Am J Physiol Cell Physiol 2010, 299(6):C1562-C1570.

53. Eliasson $P$, Rehn $M$, Hammar $P$, Larsson $P$, Sirenko O, Flippin LA, Cammenga J, Jonsson Jl: Hypoxia mediates low cell-cycle activity and increases the proportion of long-term-reconstituting hematopoietic stem cells during in vitro culture. Exp Hematol 2010, 38(4):301-310. e2.

doi:10.1186/2001-1326-3-12

Cite this article as: Simerman et al:: Pluripotent muse cells derived from human adipose tissue: a new perspective on regenerative medicine and cell therapy. Clinical and Translational Medicine 2014 3:12.

\section{Submit your manuscript to a SpringerOpen ${ }^{\odot}$ journal and benefit from:}

- Convenient online submission

- Rigorous peer review

- Immediate publication on acceptance

- Open access: articles freely available online

- High visibility within the field

- Retaining the copyright to your article

Submit your next manuscript at $>$ springeropen.com 